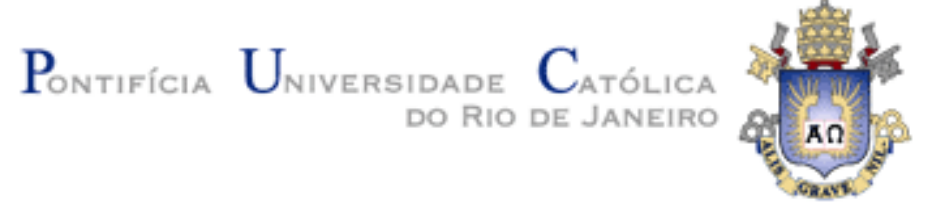

Ana Cristina de Abreu Oliveira

\author{
Justiça e Ética no pensamento \\ de Jacques Derrida
}

\begin{abstract}
Tese de Doutorado
Tese de Doutorado apresentada como requisito parcial para a obtenção do grau de Doutor pelo Programa de Pós-graduação em Filosofia da PUC-Rio

Orientador: Paulo Cesar Duque-Estrada Co-orientadora: Maria do Carmo B. de Faria
\end{abstract}


Ana Cristina de Abreu Oliveira

\section{Justiça e ética no pensamento de Jacques Derrida}

Tese apresentada como requisito parcial para obtenção do grau de Doutor pelo Programa de Pós-Graduação em Filosofia do Departamento de Filosofia do Centro de Teologia e Ciências Humanas da PUC-Rio. Aprovada pela Comissão Examinadora abaixo assinada.

Prof. Paulo Cesar Duque Estrada

Orientador

Departamento de Filosofia da PUC-Rio

Profa. Maria do Carmo Betttencourt de Faria

Co-Orientadora

USU

Profa. Andrea Bieri

Departamento de Filosofia da PUC-Rio

Prof. Olinto Pegoraro

UERJ

Profa. Dirce Eleonora Nigro Solis

UFRJ

Profa. Bethânia Albuquerque de Assy

PUC-Rio

Prof. Paulo Fernando Carneiro de Andrade

Coordenador Setorial do Centro

de Teologia e Ciências Humanas - PUC-Rio 
Todos os direitos reservados. É proibida a reprodução total ou parcial do trabalho sem autorização da universidade, do autor, do orientador e do co-orientador.

\section{Ana Cristina de Abreu Oliveira}

Graduada em Sociologia pela PUC-Rio. Mestre em Filosofia pela PUC-Rio.

Ficha Catalográfica

Oliveira, Ana Cristina de Abreu

Justiça e ética no pensamento de Jacques Derrida / Ana Cristina de Abreu Oliveira ; orientador: Paulo César Duque-Estrada ; coorientadora: Maria do Carmo B. de Faria. 2007.

166 f. ; $30 \mathrm{~cm}$

Tese (Doutorado em Filosofia)-Pontifícia Universidade Católica do Rio de Janeiro, Rio de Janeiro, 2007.

Inclui bibliografia

1. Filosofia - Teses. 2. Justiça. 3. Ética. 4. Alteridade. I. Duque-Estrada, Paulo Cesar. II. Faria, Maria do Carmo B. de. III. Pontifícia Universidade Católica do Rio de Janeiro. Departamento de Filosofia. IV. Título.

CDD: 100 


\section{Agradecimentos}

Ao CNPq, pela ajuda financeira, e ao pessoal da Biblioteca, pela presteza com que sempre fui atendida. 


\section{RESUMO}

Oliveira, Ana Cristina de Abreu; Duque-Estrada, Paulo Cesar e Bettencourt de Faria, Maria do Carmo. Justiça e ética no pensamento de Jacques Derrida, Rio de Janeiro, 2007, 166 p. Tese de Doutorado - Departamento de Filosofia. Pontifícia Universidade Católica do Rio de Janeiro.

O objetivo desta tese é estabelecer uma reflexão sobre justiça e ética em Jacques Derrida, um autor que elege o tema da justiça para falar da alteridade, e para demonstrar o que ela traz de abertura para pensar o problema da exclusão, face ao pensamento do homem e do ser como presença. Para dar conta deste objetivo, examinei a relação entre ética e humanismo em articulação com o questionamento de Derrida sobre a delimitação do homem proposta por Heidegger. A partir daí entrei na problemática que informa esta discussão, a da violência que se atualiza no jogo da linguagem em sua relação com a alteridade e, posteriormente, através da linguagem do direito. Esta discussão é acompanhada da expectativa da vinda do outro (da justiça), o que implica assumir, face aos infinitos problemas aí envolvidos, uma responsabilidade sem limite, ou ainda, implica assumir um compromisso ético com a justiça.

\section{Palavras-chave}

Justiça, ética, alteridade e filosofia 


\section{Résumé}

Oliveira, Ana Cristina de Abreu; Duque-Estrada, Paulo Cesar e Bettencourt de Faria, Maria do Carmo. Justice et étique dans la pensée de Jacques Derrida, Rio de Janeiro, 2007, 166 p. Tese de Doutorado - Departamento de Filosofia. Pontifícia Universidade Católica do Rio de Janeiro.

Le but de cette thèse est d'établir une réflexion sur la justice et l'éthique en Jacques Derrida, un auteur qui élit le thème de la justice pour parler d'altérité et pour démontrer ce qu'elle apporte d'ouverture pour penser le problème de l'exclusion en face de la pensée sur l'homme et sur l'être comme présence. Pour en rendre compte de cet objectif, j'ai examiné la relation entre l'éthique et l'humanisme en articulation avec le questionnement posé par Derrida sur la délimitation de l'homme proposée par Heidegger. À partir de cela je suis rentrée à la problématique qu'informe cette discussion, celle de la violence que s'actualise au jeu du language et sa relation avec l'altérité et, postérieurement à travers du language du Droit. Cette discussion est suivie par l'expectative de l'arrivée de l'autre (de la justice), ce qu'implique à assumer, devant les infinis problèmes y compris, une responsabilité sans limite, ou encore, ce qu'implique à l'assomption d'un compromis éthique avec la justice.

\section{Mots-Chefs}

Justice, étique, alterité, philosophie 


\section{SUMÁRIO}

1. INTRODUÇÂO

2. ÉT ICA, HUMANISMO E O FIM DO HOMEM

2.1 Introduzindo a questão

2.2 A crítica do humanismo e a questão da ética

$2.3 \mathrm{O}$ fim do homem

3. UMA LEITURA SOBRE O PENSAMENTO DE JACQUES DERRIDA

3.1 Escritura e Rastro: o questionamento derridiano sobre o conceito de linguagem

3.2 Différance e alteridade

64

3.3 Tempo e alteridade

4.1 Derrida e Agamben: duas leituras sobre A crítica da violência (Zur Kritik der Gewalt) de Walter Benjamin

4.3 Decisão, justiça e indecidível: o questionamento derridiano 
sobre a idéia de justiça presente

4.4 A justiça presente e a justiça por vir 133

4.5 O por vir e as políticas da diferença 137

5. CONSIDERAÇÕES FINAIS

6. BIBLIOGRAFIA 